\title{
HIV-1 Group M and O Nucleic Acid Measurement
}

National Cancer Institute

\section{Source}

National Cancer Institute. HIV-1 Group M and O Nucleic Acid Measurement. NCI

Thesaurus. Code C92263.

The determination of the amount of HIV-1 group $\mathrm{M}$ and $\mathrm{O}$ nucleic acid present in a sample. 